\title{
Osteitis Fibrosa Cystica: A Forgotten Entity of Primary Hyperparathyroidism
}

\author{
Manish Swarnkar
}

\begin{abstract}
Primary hyperparathyroidism (PHPT) is classically characterized by stone and bone disease, clinical bone involvement is seldom seen nowadays ( $<5 \%$ of patients). In PHPT, classical skeletal involvement can be the first sign but due to rarity of its occurrence it is no longer included in the differential diagnosis of such manifestations of skeletal diseases. Radiological (X-ray and CT scan) findings of osteitis fibrosa cystica include lytic or multilobular cystic changes [brown tumors] and these lesions can be easily misinterpreted as metastatic carcinoma, oteoclastoma, fibrous dysplasia, and especially giant cell tumor that has almost same radiological and histological features if serum calcium and parathyroid hormone (PTH) are not assessed, which are elevated only in PHPT.

Conclusion: When radiographic evidence of a lytic lesion and hypercalcemia are present, PHPT should always be considered in the differential diagnosis.

Key messages: Primary hyperparathyroidism most often is due to a parathyroid adenoma. Due to elevated PTH levels bone resorption increases, leading to polyostotic lesions and a reduction in bone mineral density. Osteitis fibrosa cystica eventually develops in patients with advanced disease and patients often require parathyroidectomy as a definitive treatment.

Keywords: Brown tumors, Multiple bony lesions, Osteitis fibrosa cystica, Primary hyperparathyroidism.

World Journal of Endocrine Surgery (2020): 10.5005/jp-journals-10002-1290
\end{abstract}

\section{INTRODUCTION}

Hyperparathyroidism classically presents with symptoms due to hypercalcemia such as abdominal and bony pain, fatigue, lethargy, urolithiasis, and psychiatric manifestations. Estimated prevalence of primary hyperparathyroidism (PHPT) is approximately $1 \%$ and most common cause is parathyroid adenoma followed by parathyroid hyperplasia; rarely, PHPT is caused by cancer of parathyroid gland. ${ }^{1}$

In developing world, making diagnosis of PHPT is difficult because of limited resource for estimation of parathyroid hormone (PTH), serum calcium, and gland imaging; moreover, anticipated hypercalcemia associated with PHPT may not be seen due to vitamin D deficiency and hypoproteinemia. ${ }^{2,3}$ Pathological fractures seen in severe hyperparathyroidism can be associated with the classical skeletal complication of hyperparathyroidism called osteitis fibrosa cystica, although it is very rare in the modern era and occurs in approximately $2 \%$ of patients. ${ }^{4}$ We describe a case of PHPT in which the first clinical manifestation of the disease was bone pain and osteolytic lesions on imaging that masqueraded as a malignancy.

\section{Case Description}

A 35-year-old female admitted in the orthopedics ward with the complaints of pain in right hip and thigh, difficulty in walking, headache, and fatigue for 2 years. The MRI of both thigh and pelvis showed multiple intramedullary solid cystic lesions involving proximal and mid-shaft both femur appearing hypointense in T1W1 images (Fig. 1A); few similar lesions were also visualized in part of ischiopubic rami and bilateral iliac blades, which was reported as metastasis or giant cell tumor. Only then was biochemical indices obtained, confirming the diagnosis of PHPT: serum calcium was $14.9 \mathrm{mg} / \mathrm{dL}(\mathrm{NL}, 8.4-10.2)$; serum phosphoruswas $1.4 \mathrm{mg} / \mathrm{dL}(\mathrm{NL}, 2.7-4.5)$.
Department of Surgery, Jawaharlal Nehru Medical College, Sawangi, Wardha, Maharashtra, India

Corresponding Author: Manish Swarnkar, Department of Surgery, Jawaharlal Nehru Medical College, Sawangi, Wardha, Maharashtra, India, Phone: +91 9763703920, e-mail: mswarnkar1971@gmail.com

How to cite this article: Swarnkar M. Osteitis Fibrosa Cystica: A Forgotten Entity of Primary Hyperparathyroidism. World J Endoc Surg 2020;12(2):98-100.

Source of support: Nil

Conflict of interest: None

Albumin was $4.1 \mathrm{~g} / \mathrm{dL}$ (NL, 3.9-4.8). Alkaline phosphatase activity was $3178 \mathrm{IU} / \mathrm{L}$ (NL, 39-177), and PTH was $203.7 \mathrm{pg} / \mathrm{mL}$ (NL, 10-65). After admission, on 3rd day the patient developed sudden pain in the right thigh on getting down from bed and on X-ray anteroposterior view there was fracture of the right proximal shaft femur (Fig. 1B). Thomas splint was applied and the patient was posted for closed reduction and internal fixation with a long proximal femoral nail. The patient was stabilized and the CECT neck was done, which showed $33 \times 24 \times 23 \mathrm{~mm}$ sized right inferior parathyroid adenoma (Fig. 1C). The patient had a successful neck exploration and right inferior parathyroidectomy was done (Fig. 2). Immediate pre-op PTH value was $679 \mathrm{pg} / \mathrm{mL}$, which dropped to $39.4 \mathrm{pg} / \mathrm{mL}$, after parathyroidectomy. The tumor weighed about $19 \mathrm{~g}$ and showed parathyroid adenoma on histology (Fig. 3). A customized hinge brace with thigh and leg support was made and given to the patient and physiotherapy with the brace was advised. The patient was in follow-up for 3 months during which there was improvement in clinical, radiological, and biochemical (serum calcium and parathyroid hormone level) parameters.

C) The Author(s). 2020 Open Access This article is distributed under the terms of the Creative Commons Attribution 4.0 International License (https://creativecommons. org/licenses/by-nc/4.0/), which permits unrestricted use, distribution, and non-commercial reproduction in any medium, provided you give appropriate credit to the original author(s) and the source, provide a link to the Creative Commons license, and indicate if changes were made. The Creative Commons Public Domain Dedication waiver (http://creativecommons.org/publicdomain/zero/1.0/) applies to the data made available in this article, unless otherwise stated. 

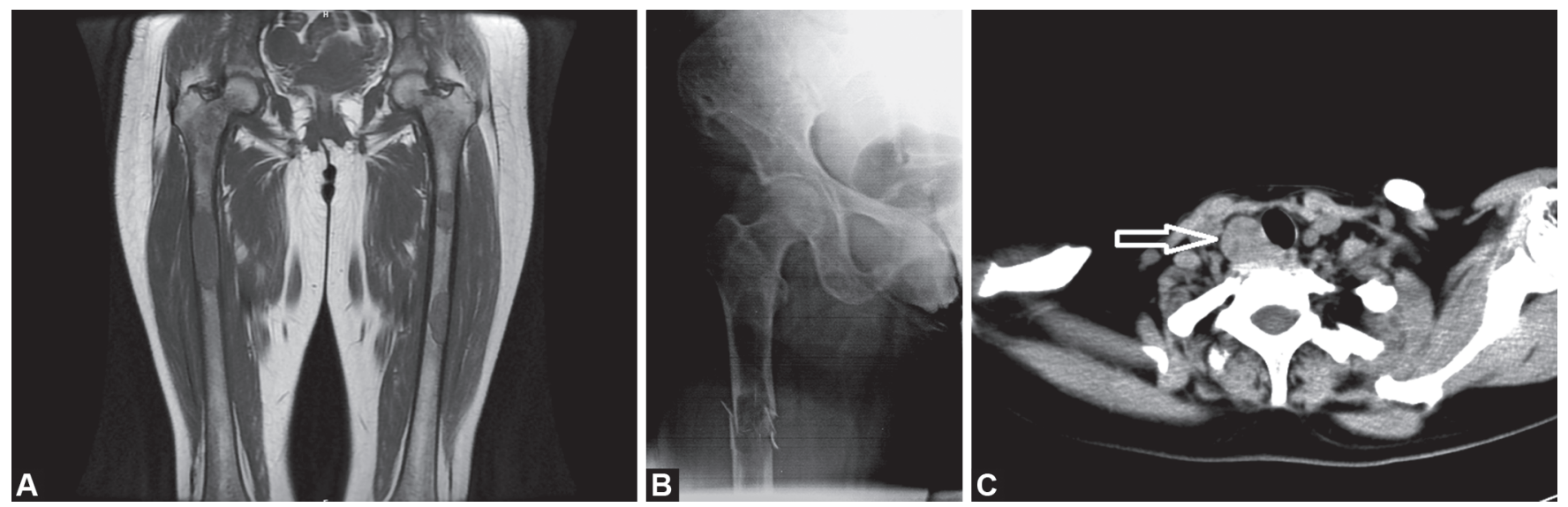

Figs 1A to C: (A) MRI (T1W1) image showing multiple brown tumors as hypointense lesions involving both femurs; (B) X-ray Rt. hip joint with femur showing pathological fracture of rt. femur; (C) CECT neck revealing rt. parathyroid adenoma (white arrow)

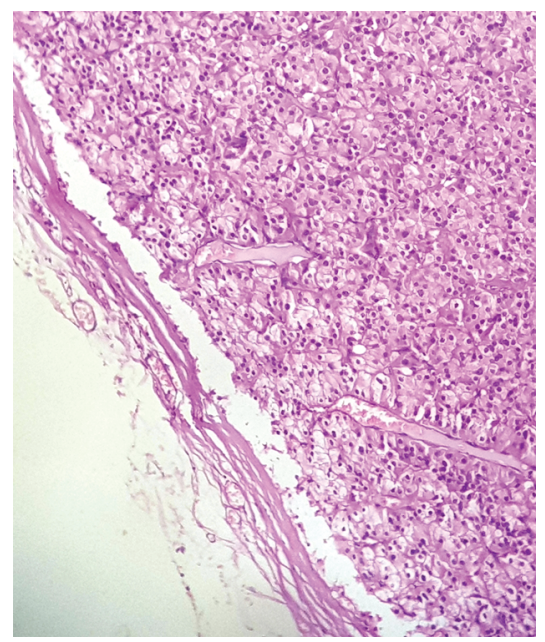

Fig. 2: H\&E stained slide with 40x view from parathyroid lesion shows encapsulated, sheets of cells composed of chief cells with some oxyphil cells in a delicate capillary network at places

\section{Discussion}

Primary hyperparathyroidism is rare. The prevalence rate varies from 1 to $4 \%$, with a female:male ratio of $3: 1 .^{5}$ In $80 \%$ of cases, the cause is a solitary adenoma and in $20 \%$ glandular hyperplasia. ${ }^{6}$ The classical symptoms and abnormalities seen in PHPT are associated with increased secretion, long-term exposure to PTH, and hypercalcemia. ${ }^{7}$ Although bone disease and stone disease are the universally accepted classical manifestations of PHPT, advanced parathyroid bone disease (osteitis fibrosa cystica) is rarely seen today $(<5 \%$ of patients).

Osteitis fibrosa cystica, the classic manifestation of PHPT, is characterized clinically by bone pain and radiographically by subperiosteal bone resorption, osteolysis of the distal clavicles, and a "salt and pepper" appearance of the skull, bone cysts, and brown tumors (BTs) of the bones. ${ }^{8}$

Brown tumors consist of fibrous tissue, woven bone, and supporting vasculature, but no matrix. The osteoclasts consume the trabecular bone that osteoblasts lay down and this front of reparative bone deposition followed by additional resorption can expand beyond the usual shape of the bone, involving the periosteum, thus causing bone pain. The characteristic brown coloration results from hemosiderin deposition into the osteolytic cysts. Hemosiderin

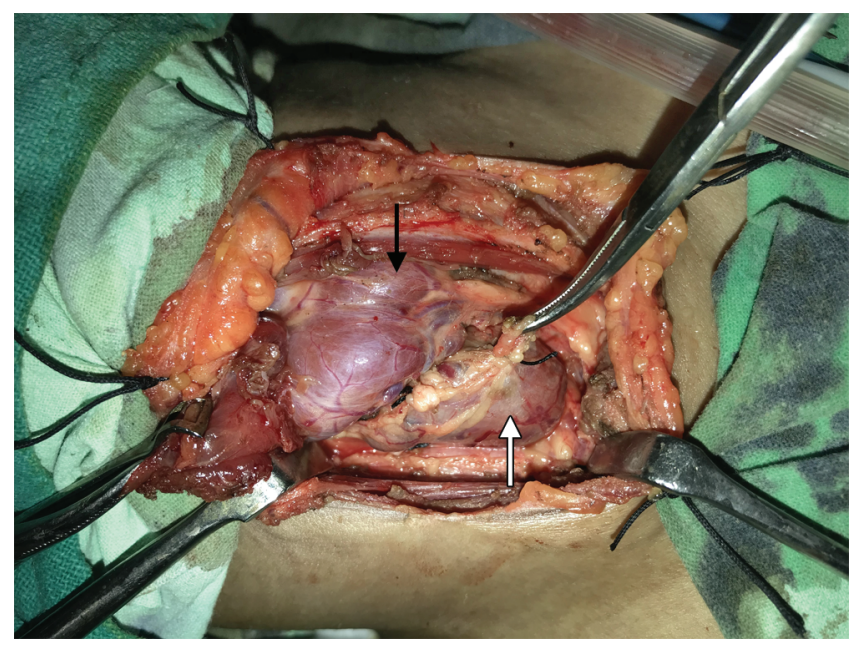

Fig. 3: Intraoperative image showing right inferior parathyroid adenoma (white arrow) and reflected thyroid gland (black arrow)

deposition is not a distinctive feature of BTs; it may also be seen in giant cell tumors of the bone. Nowadays, PHPT is mostly an asymptomatic mild disease, which is usually diagnosed by routine biochemical screening and not by the presence of typical clinical signs suggesting the disease. ${ }^{9}$ Primary hyperparathyroidism diagnosed in the context of osteitis fibrosa cystica or multiple BTs is an extremely rare condition nowadays, except in cases of severe untreated PHPT or in association with parathyroid carcinoma. ${ }^{10}$ Biochemical analysis is the only means to distinguish between the skeletal manifestation of advanced PHPT and malignancy, though hypercalcemia can be seen in advanced cancer due to osteolytic metastasis but increased PTH level in malignancy is virtually never seen. ${ }^{11,12}$

\section{Conclusion}

This case report emphasizes the need of putting osteitis fibrosa cystica in differential diagnosis of multifocal osteolytic lesions and routine assessment of serum PTH should be done in such conditions to avoid unnecessary surgical intervention.

\section{References}

1. Chan AK, Duh QY, Katz MH, et al. Clinical manifestations of primary hyperparathyroidism before and after parathyroidectomy. 
A case-control study. Ann Surg 1995;222(3):402-414. DOI: 10.1097/00000658-199509000-00017.

2. Mungadi IA, Amole AO, Pindiga UH. Primary hyperparathyroidism presenting with multiple pathological fractures and normocalcaemia. Ann Afr Med 2004;3(1):42-44.

3. Deshmukh R, AlsagoffS, Krishnan S, etal.Primary hyperparathyroidism presenting with pathological fracture. J R Coll Surg Edinb 1998;43(6):424-427.

4. Rachha R. Pathological fractures as the presenting symptom of parathyroid adenoma: a report of three cases. BJMP 2008;1: 26-29.

5. Verlaan L, van der Wal B, de Maat GJ, et al. Primary hyperparathyroidism and pathological fractures: a review. Acta Orthop Belg 2007;73(3): 300-305.

6. Yilmazlar S, Arslan E, Aksoy K, et al. Sellar-parasellar brown tumor: case report and review of literature. Skull Base 2004;14(3):163-168. DOI: 10.1055/s-2004-832261.

7. Bilezikian J, Brandi M, Rubin M, et al. Primary hyperparathyroidism: new concepts in clinical, densitometric and biochemical features.
J Intern Med 2005;257(1):6-17. DOI: 10.1111/j.1365-2796.2004 01422.x.

8. Silverberg SJ, Bilezikian JP. Evaluation and management of primary hyperparathyroidism. J Clin Endocrinol Metab 1996;81(6):2036-2040. DOI: 10.1210/jcem.81.6.8964825.

9. Khalil PN, Heining SM, Huss R, et al. Natural history and surgical treatment of brown tumor lesions at various sites in refractory primary hyperparathyroidism. Eur J Med Res 2007;12(5):222-230.

10. Panagopoulos A, Tatani I, Kourea HP, et al. Osteolytic lesions (brown tumors) of primary hyperparathyroidism misdiagnosed as multifocal giant cell tumor of the distal ulna and radius: a case report. J Med Case Rep 2018;12(1):176. DOI: 10.1186/s13256-018-1723-y.

11. Vera L, Dolcino M, Mora M, et al. Primary hyperparathyroidism diagnosed after surgical ablation of a costal mass mistaken for giantcell bone tumor: a case report. J Med Case Rep 2011;5(1):596. DOI: 10.1186/1752-1947-5-596.

12. Guliaeva S, Voloshchuk I, Mokrysheva N, et al. Maldiagnosis of giant-cell tumor of the bone in a patient with hyperparathyroid osteodystrophy. Arkh Patol 2009;71(5):53-55. 